\title{
Analisis Pengaruh Jumlah Client dan Jarak Cakupan Wireless AP IEEE 802.11N Terhadap Kualitas Jaringan WLAN Menggunakan Teknik UR dan WDS
}

\author{
(Analyze the Effect of the Number of Clients and Distance the Scope of Wireless AP \\ IEEE 802.11 n to The Quality of WLAN Networks Using UR and WDS Techniques)
}

\author{
Ilmiatul Hafazah, I Wayan Agus Arimbawa, Andy Hidayat Jatmika \\ Dept Informatics Engineering, Mataram University \\ Jl. Majapahit 62, Mataram, Lombok NTB, INDONESIA \\ Email: ilmiatul.h@gmail.com, [arimbawa, andy]@unram.ac.id
}

\begin{abstract}
This paper proposes the analyze of the effect of the number of clients and distance to the quality of WLAN networks using UR and WDS technique based on bandwidth, jitter, and packet loss parameters. The experimental results show that the quality of UR and WDS networks reduces when it has more clients and further distance. The best network quality is given by UR network for $7.5 \mathrm{~m}$, in distance with bandwidth average of $11934.7035 \mathrm{Kbps}$, jitter average $2,3563135 \mathrm{~ms}$, and the packet loss average $1.90 \%$. While the WDS network provides bandwidth $3846.9135 \mathrm{Kbps}$, average jitter $9.496095 \mathrm{~ms}$, and the packet loss average $5.23 \%$. Additionally, the worst quality network produced by WDS networks for $30 \mathrm{~m}$ distances of bandwidth average of 898.32735 Kbps, jitter average of $37.32591 \mathrm{~ms}$, and the average packet loss of $47.10 \%$, while the UR network has bandwidth of 8859,797 Kbps, the average jitter $13.082195 \mathrm{~ms}$, and the average packet loss of $19.24 \%$. It means that UR technique is superior to WDS for WLAN network.
\end{abstract}

Key words: WLAN, Wireless Distribution Systems (WDS), Universal Repeater (UR), computer networks

\section{PENDAHULUAN}

Teknologi WLAN merupakan salah satu bentuk perkembangan teknologi telekomunikasi dimana setiap orang dapat terhubung kedalam jaringan tanpa media kabel atau dengan teknologi wireless. Standar jaringan WLAN yang paling banyak beredar dipasaran saat ini adalah IEEE $802.11 \mathrm{n}$.

Jaringan WLAN dapat dibangun dengan satu buah Access Point (AP), namun untuk membangun jaringan WLAN dengan area yang lebih luas maka dibutuhkan dua atau lebih AP yang dapat dihubungkan melalui media kabel maupun tanpa kabel (wireless). Membangun jaringan WLAN dengan media kabel akan menjadi sangat rumit dan dapat menjadi kendala jika akan dilakukan pengembangan jaringan WLAN dengan cakupan area yang sangat luas yang membutuhkan banyak AP, salah satu solusi untuk membangun jaringan WLAN yang lebih praktis yakni dengan menggunakan media wireless. Sistem yang mampu mendistribusikan sinyal antar AP secara wireless yakni dengan teknik Universal Repeater (UR) dan atau dengan Wireless Distribution System (WDS).

Salah satu permasalahan dibidang infrastruktur jaringan adalah optimasi penempatan AP, dikarenakan penempatan AP secara optimal diperlukan pertimbangan dan analisis teoritis sebelum diimplementasikan. Jarak penempatan antara AP satu dengan AP yang lain merupakan salah satu faktor yang dapat menimbulkan gangguan terhadap proses pengiriman (transmitter) dan penerimaan (receiver) sinyal. Oleh karena itu, untuk membangun jaringan WLAN yang lebih praktis perlu dilakukan penelitian mengenai pengaruh jumlah client dan jarak cakupan wireless AP terhadap kualitas jaringan WLAN. Dalam hal ini, penulis akan melakukan penelitian analisis kualitas jaringan WLAN yang dibangun dengan teknik WDS dan Universal Repeater.

Pada penelitian ini dilakukan pengambilan data pada jaringan berskala kecil (testbed) yakni dengan menggunakan empat buah AP dengan standar IEEE 802.11 n. Ke empat AP tersebut akan dikonfigurasikan UR dan WDS. Analisis akan dilakukan dengan skenario tertentu dan menggunakan variasi penambahan jarak pada AP dengan parameter uji bandwidth, jitter, dan packet loss.

\section{TINJAUAN PUSTAKA}

Arif melakukan penelitian analisa kinerja jaringan WDS dengan topologi point to point. Pada penelitian tersebut menggunakan empat buah AP yang terhubung secara point to point dengan jarak masing-masing 30 meter. Pada penelitian tersebut dihasilkan Throughput maksimal dari AP-1 ke AP-2, AP-1 ke AP-3, AP-1 ke AP4 semakin turun disebabkan bandwidth yang terbagi. Nilai rata-rata Jitter terus meningkat dan masih diambang batas yang diizinkan yaitu 0-100 ms baik pada WDS-1, WDS-2, 
dan WDS-3 pada 1 client. Nilai rata-rata packet loss pada masing-masing WDS-1, WDS-2, dan WDS-3 masih dalam kategori bagus. Dari hasil pengujian berdasarkan jarak, semakin jauh jarak antar AP maka Bandwidth yang dikirim terbagi dan hasil throughtput semakin kecil [1].

Penelitian terkait lainnya yaitu optimasi ketinggian AP pada jaringan WDS [2]. Pada penelitian tersebut kualitas layanan yang diukur adalah throughput dan delay. Perancangan meliputi konfigurasi WDS dan FTP server. Pengujian dilakukan di dalam dan luar ruangan dengan variasi ketinggian AP 0,75 meter, 2 meter, 3,5 meter, dan 4 meter. Pengujian tersebut menghasilkan ketinggian optimal AP di dalam ruangan yaitu pada ketinggian 2 meter dengan throughput rata- rata sebesar 169,08 Bps, sedangkan posisi optimal AP di luar ruangan yaitu pada ketinggian 0,75 meter dengan throughput 676,08 Bps.

Pada penelitian [3] melakukan analisa kinerja jaringan WDS dengan parameter QoS yakni Delay, Packet loss, dan Jitter. Pengujian dilakukan menggunakan 1 (satu) client pada kondisi jaringan dengan dan tanpa penghalang. Faktor penghalang tembok atau beton dapat menurunkan kualitas layanan Throughput, Jitter, packet loss dan Delay pada jaringan WDS. Pengujian kinerja parameter QoS pada jaringan WDS dan non WDS diketahui bahwa terjadi penurunan Throughput pada jaringan WDS yaitu dari Throughput sebesar 15.18 Mbits/s menjadi 6.25 Mbits/s. Sedangkan perbandingan pada parameter Delay dan packet loss masuk dalam kategori sangat bagus dan parameter Jitter masuk dalam katagori sangat bagus menurut TIPHON.

Penelitian analisa kinerja implementasi Wireless Distribution System pada perangkat Access Point 802.11G menggunakan Openwrt [4] menggunakan dua buah AP dan variasi jumlah client sebanyak 1 (satu) hingga 12 (dua belas) client. Pengujian dilakukan sebanyak 10 (sepuluh) kali pada kondisi LoS dan Nlos. Dari hasil pengujian dengan banyak client terdapat satu atau dua buah client yang hanya mendapatkan sebagian kecil dari kanal yang ada. Pada kondisi LoS jaringan dengan sistem WDS memiliki pengaruh yang kecil terhadap penurunan kualitas Throughput yang diterima oleh client. Sedangkan pada kondisi NloS pada ruangan yang terpisah tembok tebal dapat menurunkan kualitas Throughput rata-rata yang diperoleh client hingga sebesar $42 \%$ dari kondisi LoS.

Berdasarkan beberapa penelitian diatas diperoleh kesimpulan bahwa jaringan WLAN dapat dibangun menggunakan teknik WDS. Selain WDS, teknik UR dapat diimplementasikan untuk membangun jaringan WLAN.

\section{TEKNIK UR DAN WDS}

UR dan WDS memiliki definisi yang sama yaitu sistem distribusi jaringan wireless yang saling terhubung antar perangkat AP tanpa harus menggunakan kabel sebagai media transfer data sehingga cakupan jaringan wireless menjadi lebih luas. UR dan WDS setidaknya hanya menggunakan satu kabel jaringan sebagai jalur backbone pada perangkat AP utama (Root AP), sedangkan pada AP lainnya meneruskan sinyal dari backbone yang berasal dari
Root AP secara wireless. Pada WDS dilakukan penyetaraan layanan berdasarkan mac address, pada saat satu mac address dilayani maka mac address lain harus menunggu, berbeda dengan UR yang melakukan pelayanan secara keseluruhan dan bersamaan dengan paket yang besar.

Universal Repeater (UR) yakni suatu perangkat radio yang berfungsi sebagai penguat sinyal dari AP agar sinyal wireless tetap stabil. Mode wireless Repeater hanya berperan sebagai penguat sinyal sehingga tidak dapat dikoneksikan oleh host secara langsung. Karena tidak terhubung secara langsung ke jaringan kabel maka wireless repeater akan sangat tergantung pada root AP. Root AP merupakan Access Point yang terhubung ke sistem jaringan kabel. UR bekerja dengan cara menangkap sinyal dari root AP, kemudian dikuatkan kembali sehingga dapat diterima oleh client wireless yang jauh. UR berkomunikasi dengan client sama baiknya pada Access Point upstream melalui koneksi wireless, mengurangi throughput pada wireless segmen. Pengguna dapat membebankan pada koneksi wireless akan mengalami throughput keluaran yang rendah dan meningkatnya keterpendaman pada skenario ini. Pada dasarnya untuk port Ethernet kabel dapat dihentikan ketika dalam mode ini [5].

Wireless Distribution System (WDS) yaitu sistem distribusi jaringan nirkabel yang saling terhubung antar perangkat AP tanpa harus menggunakan kabel sebagai media transfer data sehingga cakupan jaringan wireless menjadi lebih luas. Memanfaatkan jalur nirkabel dari setiap perangkat AP. WDS dapat diimplementasikan dengan mengkonfigurasikan AP dengan fitur WDS. Hal ini berbeda dengan cara yang digunakan pada umumnya dengan menggunakan media kabel sebagai sistem distribusi (wired LAN) pada jaringan. Semua base station dalam WDS harus dikonfigurasikan dengan menggunakan channel radio yang sama, metode inkripsi (tanpa enkripsi, WEP, atau WPA) dan juga pada kunci enkripsi yang sama. Dimana koneksi berupa konfigurasi dengan menggunakan Service Set Identifiers (SSID) yang berbeda pada setiap identitas pengguna [1].

Parameter-parameter yang digunakan pada penelitian diantaranya bandwidth, jitter, dan packet loss dapat digunakan untuk mengetahui kualitas dari jaringan WLAN. Bandwidth atau yang dikenal sebagai lebar pita merupakan suatu ukuran dari banyaknya informasi yang dapat mengalir dari suatu tempat ke tempat lain dalam suatu waktu tertentu. Bandwidth dapat dipakai untuk mengukur baik aliran data analog maupun aliran data digital. Satuan yang digunakan untuk bandwidth adalah bps (bit per second) [6].

Jitter merupakan variasi delay antar paket yang terjadi pada jaringan IP. Besarnya nilai Jitter akan sangat dipengaruhi oleh variasi beban trafik dan besarnya tumbukan antar paket (congestion) yang ada dalam jaringn IP dimana standar jitter dapat dilihat pada Tabel I. Semakin besar beban trafik di dalam jaringan akan menyebabkan 
semakin besar pula peluang terjadinya congestion dengan demikian nilai Jitter akan semakin besar [6].

TABEL I. STANDAR JITTER MENURUT THIPON

\begin{tabular}{|c|c|}
\hline Waktu tunda (ms) & Kualitas \\
\hline 0 & Sangat Baik \\
\hline $1-75$ & Baik \\
\hline $76-125$ & Cukup \\
\hline$>225$ & Buruk \\
\hline
\end{tabular}

Packet loss adalah banyaknya paket yang hilang selama proses transmisi ke tujuan. Paket hilang terjadi ketika satu atau lebih paket data yang melewati suatu jaringan gagal mencapai tujuannya [6]. Standar Packet Loss dapat dilihat pada Tabel II.

TABEL II. STANDAR PACKET LOSS MENURUT THIPON

\begin{tabular}{|c|c|}
\hline Packet loss (\%) & Kualitas \\
\hline $0-2 \%$ & Sangat Baik \\
\hline $3-14 \%$ & Baik \\
\hline $15-24 \%$ & Cukup \\
\hline$>25 \%$ & Buruk \\
\hline
\end{tabular}

\section{Metodologi Penelitian}

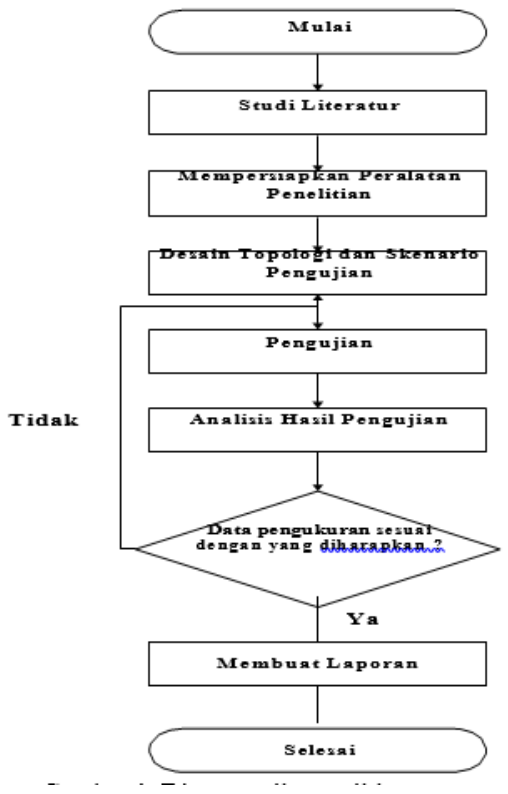

Gambar 1 Metodologi Penelitian

Gambar 1 merupakan gambaran aliran proses penelitian analisa pengaruh jumlah client dan jarak wireless AP terhadap kualitas jaringan WLAN menggunakan teknik UR dan WDS. Penelitian ini merupakan model incremental, model incremental merupakan model untuk pengembangan sistem yang didasari pada requirement yang dibagi menjadi beberapa bagian sehingga pengembangan nya secara bertahap.

\section{A. Studi Literatur}

Pada studi literatur, dimulai dengan mempelajari konsep serta teori pendukung dan segala sesuatu yang berkaitan dengan yang akan diteliti dalam hal ini jaringan WDS dan Universal repeater yang didapatkan dari perpustakaan dan internet baik berupa buku maupun jurnal ilmiah.

\section{B. Persiapan Peralatan Penelitian}

Persiapan hardware dan software yang mendukung penelitian diantaranya empat buah AP, laptop, dan aplikasi Jperf.

\section{Desain Topologi Penelitian}

Pada Penelitian ini akan menggunakan topologi point to point yang terdiri dari empat buah AP yang dapat dijelaskan secara garis besar seperti Gambar 2 .

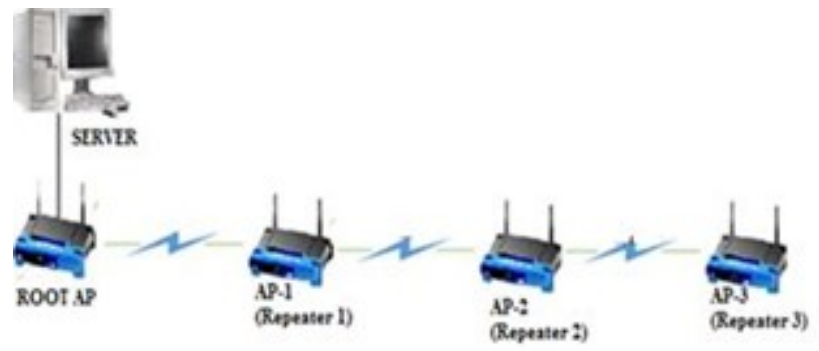

Gambar 2. Rancangan topologi penelitian

Penelitian ini dilakukan dengan dua skenario pengukuran yaitu satu client dan tiga client yang diposisikan pada masing-masing AP dapat dijelaskan pada Gambar 3 dan Gambar 4.

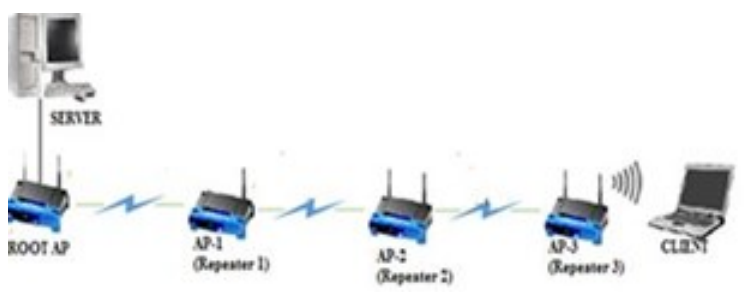

Gambar 3. Skenario pengujian dengan satu client

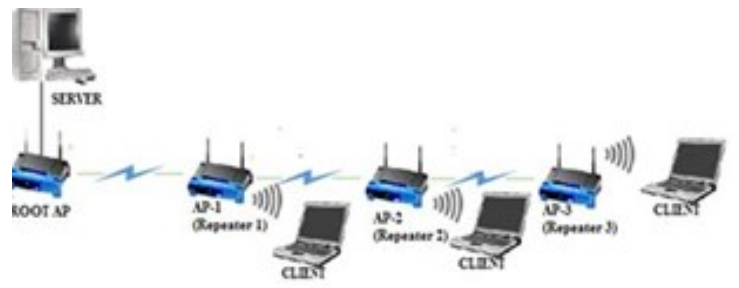

Gambar 4. Skenario Pengujian dengan tiga client

Pada Gambar 3 pengukuran ini dilakukan dengan menggunakan dua buah laptop dan empat buah AP, dimana laptop pertama sebagai server terhubung langsung dengan root AP menggunakan kabel UTP, laptop kedua sebagai client terhubung dengan AP secara wireless, kemudian satu buah AP sebagai Root AP dan 
tiga lainnya sebagai AP repeater. Pada skenario ini laptop client akan diletakkan di sekitar AP-3 sedangkan pada AP-1 dan AP-2 tidak terdapat client.

Pada Gambar 4 skenario pengukuran dilakukan dengan menggunakan empat buah laptop dan empat buah AP, dimana laptop pertama sebagai server terhubung langsung dengan root AP menggunakan kabel UTP, dan tiga laptop lainnya sebagai client terhubung dengan AP secara wireless, kemudian satu buah AP sebagai Root AP dan tiga lainnya sebagai AP repeater. Pada skenario ini diletakkan masing-masing satu client di sekitar AP repeater.

Pada masing-masing skenario akan dilakukan tiga pengukuran yakni berdasarkan variasi jarak AP seperti yang di tunjukan pada Gambar 5, Gambar 6, dan Gambar 7.

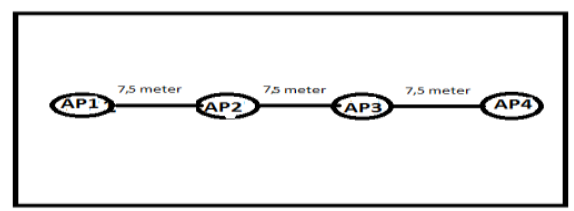

Gambar 5. Layout Posisi antar AP dengan Jarak 7,5 Meter

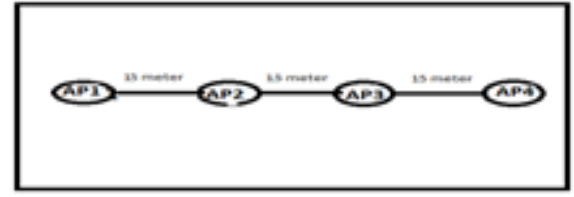

Gambar 6. Layout Posisi antar AP dengan Jarak 15 Meter

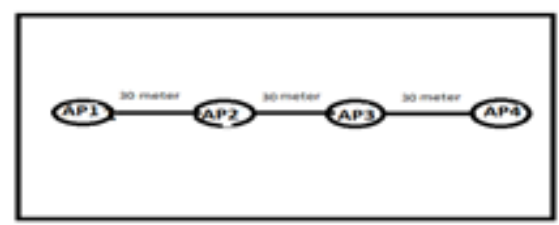

Gambar 7. Layout Posisi antar AP dengan Jarak 30 Meter

- $\quad$ Pada Gambar 5, jarak dari AP1 ke AP2 sejauh 7,5 meter, AP2 ke AP3 7,5 meter dan AP3 ke AP4 7,5 meter.

- Pada Gambar 6, jarak dari AP1 ke AP2 sejauh 15 meter, AP2 ke AP3 15 meter dan AP3 ke AP4 15 meter.

- Pada Gambar 7, jarak dari AP1 ke AP2 sejauh 30 meter, AP2 ke AP3 30 meter dan AP3 ke AP4 30 meter.

\section{Parameter-Parameter Pengujian}

Parameter yang akan di uji atau di ukur dalam penelitian ini adalah bandwidth, jitter, dan packet loss. Pengukuran parameter ini menggunakan software Jperf sebagai traffic injector.

\section{HASIL DAN PEMBAHASAN}

Hasil analisa pengaruh jumlah client dan jarak cakupan wireless AP IEEE 802.11 n terhadap kualitas jaringan WLAN menggunakan teknik UR dan WDS ditampilkan dalam bentuk perbandingan UR dan WDS berdasarkan skenario dan parameter pengujian yakni bandwidth, jitter, dan packet loss.

\section{A. Perbandingan UR dan WDS Berdasarkan Skenario}

Hasil perbandingan UR dan WDS berdasarkan skenario 1 dapat dilihat pada Gambar 8, Gambar 9, dan Gambar 10. Sedangkan Hasil perbandingan UR dan WDS berdasarkan skenario 2 dapat dilihat pada Gambar 11, Gambar 12, dan Gambar 13.

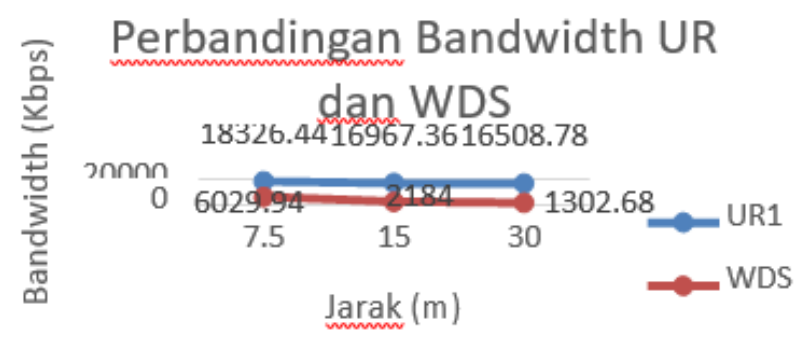

Gambar 8. Grafik Perbandingan Bandwidth UR dan WDS Skenario 1

Berdasarkan Gambar 8 dapat diketahui bahwa dengan jumlah client satu bandwidth yang dihasilkan jaringan UR lebih besar dibandingkan WDS.

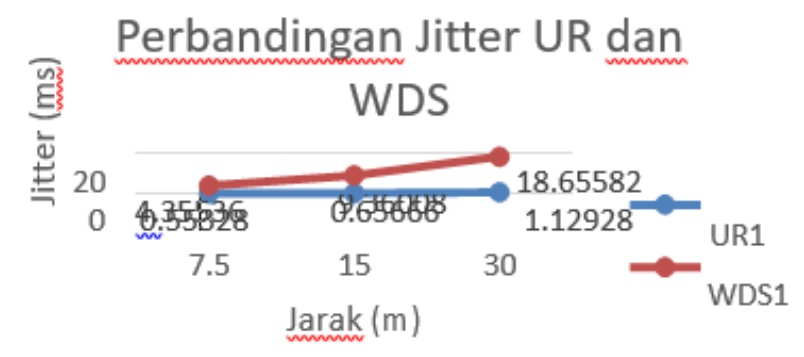

Gambar 9. Grafik Perbandingan Jitter UR dan WDS Skenario 1

Berdasarkan Gambar 9 dapat diketahui bahwa dengan jumlah client satu jitter yang dihasilkan jaringan WDS jauh lebih besar dibandingkan UR.

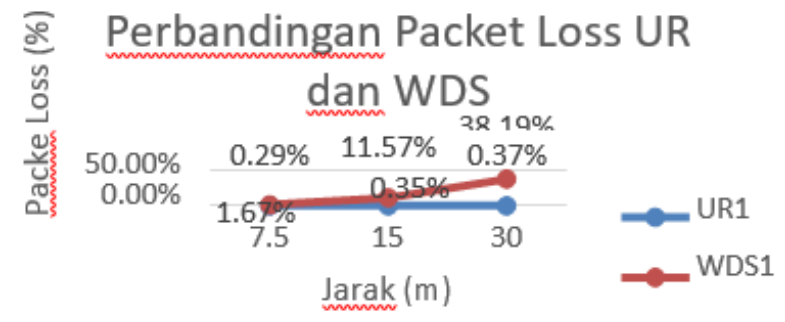

Gambar 10. Grafik Perbandingan Packet Loss UR dan WDS Skenario 1

Berdasarkan Gambar 10, dapat diketahui bahwa dengan jumlah client satu, Packet Loss yang dihasilkan jaringan WDS jauh lebih besar dibandingkan UR. Berdasarkan Gambar 11, dapat diketahui bahwa dengan jumlah client tiga Bandwidth yang dihasilkan jaringan UR jauh lebih besar dibandingkan WDS. Berdasarkan Gambar 12 dapat diketahui bahwa dengan jumlah client tiga Jitter yang dihasilkan jaringan WDS jauh lebih besar dibandingkan UR. 


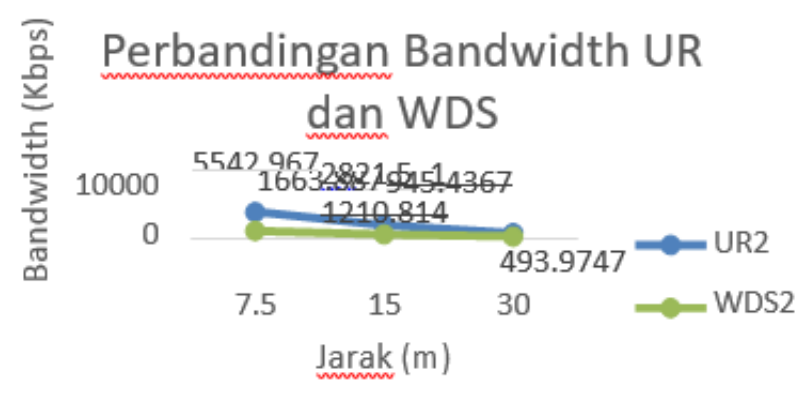

Gambar 11. Grafik Perbandingan Bandwidht UR dan WDS Skenario 2

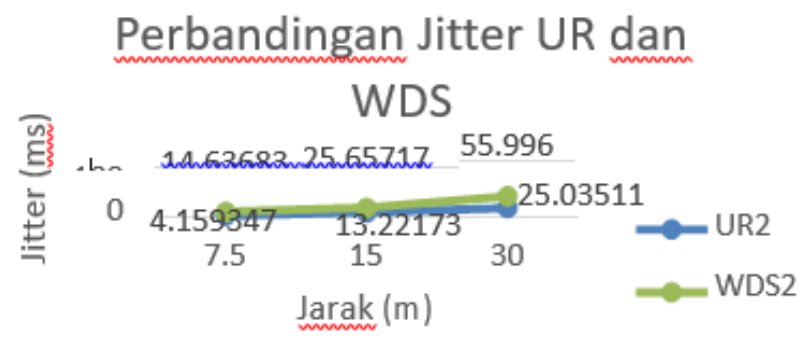

Gambar 12. Grafik Perbandingan Jitter UR dan WDS Skenario 2

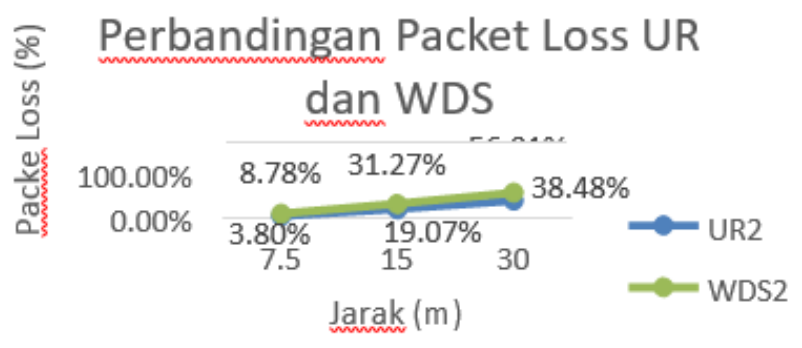

Gambar 13. Grafik Perbandingan Packet Loss UR dan WDS Skenario 2

Berdasarkan Gambar 13 dapat diketahui bahwa dengan jumlah client tiga Packet Loss yang dihasilkan jaringan WDS jauh lebih besar dibandingkan UR.

\section{B. Perbandingan UR dan WDS Berdasarkan Parameter Pengujian}

Berikut adalah grafik hasil perbandingan UR dan WDS berdasarkan parameter pengujian yakni bandwidth, jitter, dan packet loss, diperlihatkan pada Gambar 14, Gambar 15, dan Gambar 16.

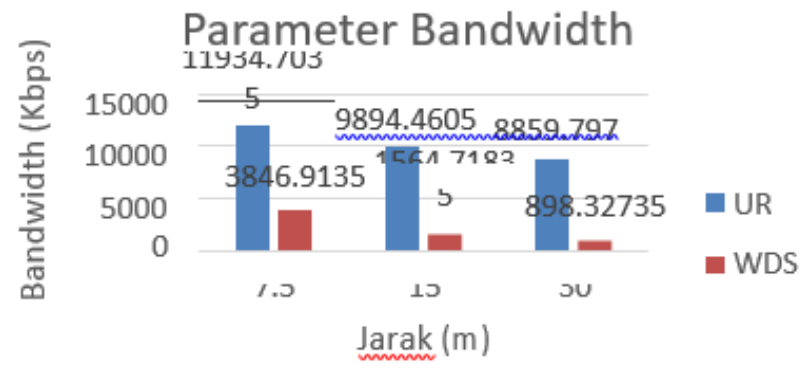

Gambar 14. Grafik Perbandingan UR dan WDS berdasarkan Bandwidth

Berdasarkan Gambar 14 dapat dilihat bahwa dari keseluruhan jarak, bandwidth yang diterima oleh jaringan UR jauh lebih besar dibandingkan bandwidth yang diterima jaringan WDS, hal tersebut disebabkan pada jaringan WDS harus re-transmit informasi selama komunikasi antar AP WDS, sehingga semakin banyak AP dan semakin jauh jarak antar AP maka akan semakin kecil pula bandwidth yang diterima client.

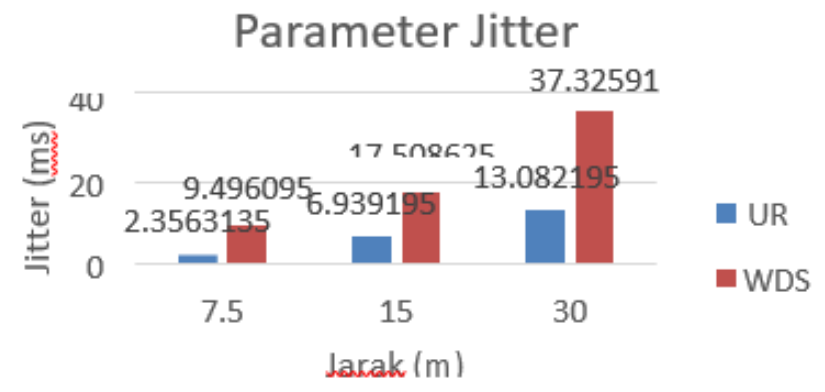

Gambar 15. Grafik Perbandingan UR dan WDS berdasarkan Jitter

Berdasarkan Gambar 15, dapat dilihat bahwa dari keseluruhan jarak jitter terkecil dihasilkan pada jaringan. Jitter yang didapatkan jaringan WDS lebih besar disebabkan AP WDS harus menerima dan mengirim setiap frame pada kanal radio yang sama, mengakibatkan terjadinya penggandaan jumlah traffic.

\section{Parameter Packet Loss}

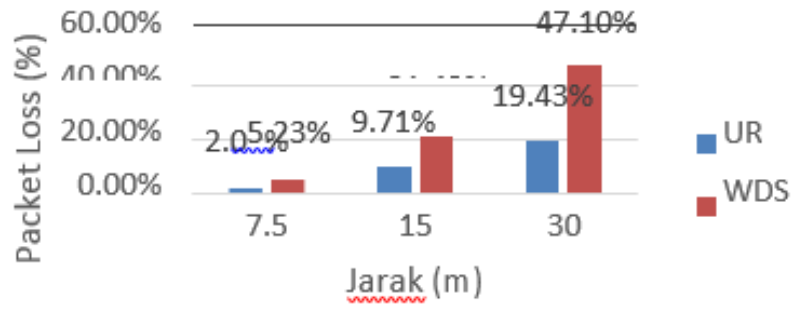

Gambar 16. Grafik Perbandingan UR dan WDS berdasarkan Packet loss

Berdasarkan Gambar 16, dapat dilihat bahwa dari keseluruhan jarak, packet loss yang diterima oleh jaringan UR jauh lebih kecil dibandingkan packet loss yang diterima jaringan WDS, paket data yang hilang disebabkan terjadinya overload trafik di dalam jaringan dan banyaknya tumbukan antar paket (collision) yang ada dalam jaringan pada saat pengiriman data.

Dari analisis, hasil keseluruhan pengukuran data yang telah dilakukan baik dari parameter bandwidth, jitter, dan packet loss diketahui bahwa jaringan UR lebih unggul dibandingkan WDS.

\section{KESIMPULAN DAN SARAN}

Kesimpulan yang dapat diambil pada penelitian ini adalah:

1. Semakin jauh jarak antar AP menyebabkan penurunan kualitas jaringan WLAN baik menggunakan teknik UR maupun WDS.

2. Semakin banyak jumlah client yang terhubung dalam jaringan menyebabkan penurunan kualitas jaringan WLAN baik menggunakan teknik UR maupun WDS. 
3. Kualitas jaringan terbaik dihasilkan jaringan UR pada jarak 7,5m dengan rata-rata bandwidth sebesar $11934.7035 \mathrm{Kbps}$, rata-rata jitter sebesar $2.3563135 \mathrm{~ms}$, dan rata-rata packet loss sebesar $2.05 \%$ dibandingkan jaringan WDS dengan ratarata bandwidth $3846.9135 \mathrm{Kbps}$, rata-rata jitter $9.496095 \mathrm{~ms}$, dan rata-rata packet loss $5.23 \%$.

4. Kualitas jaringan terburuk dihasilkan jaringan WDS pada jarak $30 \mathrm{~m}$ dengan rata-rata bandwidth sebesar 898.32735 Kbps, rata-rata jitter sebesar $37.32591 \mathrm{~ms}$, dan rata-rata packet loss sebesar $47.10 \%$ dibandingkan jaringan UR dengan rata-rata bandwidth $8859.797 \mathrm{Kbps}$, ratarata jitter $13.082195 \mathrm{~ms}$, dan rata-rata packet loss $19.43 \%$.

5. Hasil analisa keseluruhan pengukuran data yang telah dilakukan diketahui bahwa jaringan UR lebih unggul dibandingkan WDS dalam membangun jaringan WLAN dengan jarak yang relatif jauh dan mampu melayani client dengan jumlah yang relatif banyak.

Adapun saran untuk pengembangan penelitian ini adalah sebaiknya menggunakan parameter pengukuran lainnya seperti troughput dan delay, serta dengan standar jaringan yang terbaru.

\section{DAFTAR PUSTAKA}

[1] A. Sayed, "Analisis Kinerja Access Point 802.11g pada Jaringan Wireless Distribution System dari Sisi Client Menggunakan Topologi Point To Point," ETD Unsyiah, 2014. .

[2] F. N. Sandy, W. A. Syafei, and I. Santoso, “Optimasi Ketinggian Access Point Pada Jaringan Wireless Distribution System," Transient, vol. 4, no. 2, p. 356, 2015.

[3] S. Nurprasetyo and Kusnawi, "Analisis Kinerja WDS (Wireless Distribution System) dengan Menggunakan Tl-Wr841nd Sebagai Wireless Repeater," Repository Universitas Amikom Yogyakarta, 2015. .

[4] D. L. A. Putra and A. S. KH, "Analisa Kinerja Implementasi Wireless Distribution System Pada Perangkat Access Point 802.11 G," J. Ilm. Politek. Elektron. Inst. Teknol. Sepuluh Nop., pp. 1-6, 2011.

[5] S. Mulyana, Mengenal WiFi Lebih Dekat. 2013.

[6] A. Hidayat, "Analisa Quality of Service (QoS) Jaringan Internet Kampus (Studi Kasus: UIN Suska Riau)," Repository UIN SUSKA RIAU, 2014. 